\title{
Efficacy, safety, and patient preference of monoamine oxidase $B$ inhibitors in the treatment of Parkinson's disease
}

REVIEW

\section{Bradley J Robottom}

Department of Neurology, University of Maryland School of Medicine, Baltimore, MD, USA
Correspondence: Bradley J Robottom Assistant Professor, Department of Neurology, University of Maryland School of Medicine, I I 0 S. Paca Street, Rm 3-S-I28, Baltimore, MD 2120I, USA Tel +I 4I0328 8586

$\mathrm{Fax}+$ I 4103280167

Email brobottom@som.umaryland.edu
This article was published in the following Dove Press journal:

Patient Preference and Adherence

19 January 2011

Number of times this article has been viewed

\begin{abstract}
Parkinson's disease (PD) is the second most common neurodegenerative disease and the most treatable. Treatment of PD is symptomatic and generally focuses on the replacement or augmentation of levodopa. A number of options are available for treatment, both in monotherapy of early PD and to treat complications of advanced PD. This review focuses on rasagiline and selegiline, two medications that belong to a class of antiparkinsonian drugs called monoamine oxidase B (MAO-B) inhibitors. Topics covered in the review include mechanism of action, efficacy in early and advanced $\mathrm{PD}$, effects on disability, the controversy regarding disease modification, safety, and patient preference for MAO-B inhibitors.
\end{abstract}

Keywords: monoamine oxidase inhibitors, rasagiline, selegiline, Parkinson's disease, efficacy, safety

\section{Introduction}

Parkinson's disease (PD) is the second most common neurodegenerative disease and the most treatable. PD affects more than one million people in the US, including $1 \%$ of the population older than 55 years. ${ }^{1}$ The diagnosis of PD is clinical, based on the presence of bradykinesia plus rigidity, tremor, or postural instability, as well as a typical history. Once the diagnosis of PD is made, symptomatic treatment may be started with a variety of agents. Treatment of PD generally focuses on the replacement or augmentation of levodopa. The most potent first-line agents are the dopamine agonists and levodopa. ${ }^{2}$ For patients who require only mild symptomatic benefit or who prefer a simpler treatment regimen, monoamine oxidase $\mathrm{B}$ (MAO-B) inhibitors are a reasonable first choice for treatment. ${ }^{2}$ The MAO-B inhibitors approved for use in PD include selegiline $\left(\right.$ Eldepryl $^{\circledR}$, Zelapar ${ }^{\circledR}$ ), and rasagiline $\left(\right.$ Azilect $\left.^{\circledR}\right)$. As PD progresses, motor complications, including "wearing off", may occur. "Wearing off" is a phenomenon characterized by periods of decreasing effectiveness of medication, leading up to the next dose. MAO-B inhibitors, in addition to their usefulness as first-line therapy, may also be used to lessen the degree of "wearing off" in advanced PD. ${ }^{3}$ This review will examine the role of MAO-B inhibitors in PD, focusing on mechanism of action, efficacy, safety, and patient preferences.

\section{Mechanism of action of MAO-B inhibitors}

Monoamines are a subset of weakly basic organic compounds containing a nitrogen group. The monoamines that are important in neurotransmission include dopamine, norepinephrine, and 5-hydroxytryptamine. ${ }^{4}$ Monoamines are catabolized by an 
intracellular enzyme called monoamine oxidase, which is located in the mitochondrial membrane. ${ }^{4,5} \mathrm{MAO}-\mathrm{B}$ is the major metabolic step for changing active dopamine to its inactive catabolites, 3,4-dihydroxyphenylacetic acid and homovanillic acid. MAO-B is the subtype of MAO inhibitor that is primarily found in the brain, accounting for $70 \%-80 \%$ of MAO in the brain. ${ }^{5,6}$ The MAO-B inhibitors selegiline and rasagiline are both selective and at commonly used $\mathrm{PD}$ doses do not have significant effects on MAO-A. Both selegiline and rasagiline bind irreversibly to MAO-B., Selegiline forms a covalent bond with MAO, leading to an irreversible effect that is limited by the tissue half-life of selegiline (2-10 days). ${ }^{5}$ Like selegiline, the binding of rasagiline to MAO is irreversible, but its pharmacodynamic effect is not. Because the turnover time of MAO-B is relatively short (6-30 days in animal models), even irreversible inhibition does not lead to a permanent effect. ${ }^{5}$

The antiparkinsonian effect of MAO-B inhibitors is primarily attributed to the inhibition of MAO-B, which decreases the rate of turnover of striatal dopamine. ${ }^{8}$ For a patient with early PD who has depressed levels of striatal dopamine, the elevation of endogenous dopamine that occurs with MAO-B inhibitors leads to a mild symptomatic benefit. ${ }^{9}$ For patients with advanced PD who are experiencing "wearing off", the principle is essentially the same. By blocking the breakdown of dopamine produced from exogenous levodopa, the effectiveness of the exogenous levodopa may be extended. The primary difference between early and advanced patients is that when used as monotherapy for early PD, MAO-B inhibitors are primarily acting on endogenous dopamine, whereas those with advanced PD and combination therapy are deriving benefits from MAO-B inhibition of catabolism of exogenous dopamine.

\section{Efficacy of MAO-B inhibitors Clinically important difference}

Efficacy data in trials of MAO-B inhibitors must be examined in light of their indication. In early PD, efficacy has been determined by change in the Unified Parkinson's Disease Rating Scale (UPDRS) ${ }^{10}$ or by delay in the time to initiation of dopaminergic therapy. The UPDRS is a widely used scale with four sections. Part I assesses mentation, behavior, and mood. Part II assesses activities of daily living (ADL). Part III is the motor examination. Part IV assesses complications of therapy. The total scale comprises 199 points, with the motor examination accounting for 108 points. When using the UPDRS as a measure of efficacy for a symptomatic therapy, it is imperative to consider what is clinically meaningful, not just statistically significant. The clinically important difference (CID) on the UPDRS has been determined using an anchor-based analysis that ties changes in the UPDRS to changes in patient-centric measures of quality of life (QOL) and disability. ${ }^{11} \mathrm{~A}$ minimal CID requires a change in the total UPDRS (T-UPDRS) of 4.3 points or 2.5 points on the motor UPDRS (M-UPDRS). A moderate CID requires a change in the T-UPDRS of 9.1 points or 5.2 points on the M-UPDRS. A large CID requires a change in the T-UPDRS of 17.1 points or 10.8 points on the M-UPDRS. ${ }^{11}$ In advanced PD, efficacy is defined as a reduction in "off" time or an increase in "on" time. "Off" time consists of that period where medication effectiveness is reduced or absent, manifested clinically by increased tremor, rigidity, or slowness. In contrast, "on" time is the time during which antiparkinsonian medication is producing a beneficial clinical response. In clinical practice, this is generally measured through the clinical interview, but in clinical trials it can also be measured by Part IV of the UPDRS or through the use of a standardized diary. ${ }^{12}$

\section{Symptomatic therapy in early \\ Parkinson's disease}

Selegiline has been demonstrated in two large, randomized, double-blinded trials to provide a symptomatic benefit when used as monotherapy. ${ }^{13,14}$ When compared with placebo, there is an improvement of 2.7 points in the T-UPDRS and 1.5 points in the M-UPDRS. ${ }^{14}$ Additionally, selegiline delays the need to initiate therapy with levodopa. In the largest study to date, DATATOP (Deprenyl and Tocopherol Antioxidative Therapy of Parkinsonism), selegiline delayed the need for treatment with levodopa by almost 9 months. ${ }^{13}$ Smaller studies have found similar, though less dramatic, benefits with a 4- to 7-month delay before the need for levodopa treatment. ${ }^{14-16}$ An additional finding from these studies is that patients taking selegiline require less levodopa once treatment

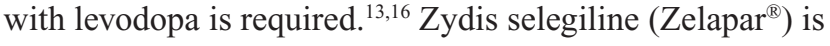
an orally disintegrating formulation that has been proven to have equivalent efficacy to oral tablets of selegiline and represents an alternative route of administration that may be beneficial for certain patients. ${ }^{17}$

Like selegiline, rasagiline has also been proven to provide a modest symptomatic benefit when used as monotherapy in patients with early PD. The TEMPO (Rasagiline Mesylate [TVP-1012] in Early Monotherapy for Parkinson's Disease Outpatients) and ADAGIO (Attentuation of Disease Progression with Azilect Given Once Daily) trials both demonstrated a clear symptomatic benefit of rasagiline. ${ }^{18,19}$ Each trial recruited patients with early PD who were naïve to antiparkinsonian 
therapy. When compared with placebo, rasagiline once daily at a dose of $1 \mathrm{mg}$ improved the T-UPDRS by 3-4.2 points and the M-UPDRS by 2.7 points. ${ }^{18,20}$ Unlike the early selegiline trials, rasagiline failed to demonstrate a decreased need for levodopa. ${ }^{18}$ The changes seen in disease severity are in the range of what can be considered a minimal CID.

\section{Symptomatic therapy in advanced Parkinson's disease}

In addition to their use as monotherapy for early PD, MAO-B inhibitors may be used as adjunctive therapy in patients with moderate to advanced PD who are experiencing motor fluctuations, specifically the "wearing off" phenomenon. The goal of therapy in advanced PD is to provide a smoother response to levodopa. In patients whose dopaminergic medication loses effectiveness before the next dose is due, options for treating "wearing off" include more frequent dosing of levodopa or adding an adjunct medication. The adjuncts that may be added in this case include catechol-O-methyl transferase inhibitors, dopamine agonists, amantadine, and MAO-B inhibitors. ${ }^{3}$ Selegiline and rasagiline, when used in advanced PD with motor fluctuations, both reduce "off" time.

Selegiline has been studied in double-blind studies in advanced PD and been shown to improve "wearing off". ${ }^{21-24}$ The amount of time spent in the "off" state may be reduced by as much as 2.2 hours per day (versus a 0.6-hour reduction in the placebo group). ${ }^{24}$ Many patients may experience a worsening of dyskinesias after starting treatment with selegiline, and in this situation the recommended course of action is to decrease the dose of levodopa. ${ }^{23}$ Whether or not selegiline improves the quality of the "on" time experienced by patients is debatable, with some studies showing no benefit to quality of "on" time, ${ }^{23}$ and others reporting more than 1 additional hour per day of dyskinesia-free "on" time. ${ }^{24}$ In addition to its effects on reduction of "off" time, selegiline may lead to improvement in other aspects of advanced PD, such as dysarthria, hypomimia, sialorrhea, and freezing of gait (FOG). ${ }^{23,25}$ The severity of "off" time in patients treated with selegiline may also be reduced. ${ }^{26}$

Like selegiline, rasagiline is useful for amelioration of "wearing off" in advanced PD. ${ }^{3}$ Two large, multicenter trials have shown that rasagiline reduces "off" time by 1.18-1.85 hours. ${ }^{27,28}$ In the PRESTO trial (A Randomized Placebo-controlled Trial of Rasagiline in Levodopa-treated Patients with Parkinsons Disease and Motor Fluctuations), 472 patients with a minimum "off" time of 2.5 hours per day were followed for 26 weeks. At the clinical dose of rasagiline most commonly used ( $1 \mathrm{mg})$, “off" time was reduced by 1.85 hours (versus 0.91 hours for placebo). A statistically significant increase in "on" time with troublesome dyskinesias occurred in the group randomized to rasagiline. ${ }^{27}$ In the LARGO trial (Lasting effect in Adjunct therapy with Rasagiline Given Once Daily), 687 participants were randomized to placebo, rasagiline, or entacapone. The primary outcome of change in "off" time showed that rasagiline ( -1.18 hours) and entacapone ( -1.20 hours) had roughly equivalent and beneficial effects compared with placebo ( -0.4 hours) ${ }^{28}$ One feature that differentiated entacapone from rasagiline was disease severity in the "off" state, where rasagiline was superior to entacapone or placebo. ${ }^{28}$ Unlike in the PRESTO trial, there was no increase in troublesome dyskinesias in the LARGO trial. There was a small, statistically significant reduction in daily levodopa dose in both of the active treatment arms (-24 mg per day in the rasagiline arm; $-19 \mathrm{mg}$ per day in the entacapone arm). ${ }^{28}$ A preplanned auxiliary study of LARGO evaluated FOG using the Freezing of Gait Questionnaire and demonstrated that subjects taking rasagiline had less FOG than those taking placebo. ${ }^{28}$

\section{Disability}

In addition to their effects on disease severity, MAO-B inhibitors may improve measures of disability in PD. The literature regarding MAO-B inhibitors and disability is complicated, in part because many studies have used the term "disability" interchangeably with disease severity. MAO-B inhibitors appear to reduce disability compared with placebo; what is unclear is whether or not they provide any additional benefit beyond other antiparkinsonian agents. Although the two are certainly related, disability and disease severity are distinct entities. ${ }^{29}$ Disability refers to the decrease or loss of ability due to an impairment to accomplish a task. ${ }^{29}$ Trials of MAO-B inhibitors that have included dedicated disability scales contain mixed results. In the LARGO trial, even in the "off" state, rasagiline led to a significant improvement on the Schwab and England Activities of Daily Living Scale, a scale that estimates the ability of PD patients to carry out a number of ADLs. ${ }^{28,30}$ Examining the UPDRS Part II ADL subscale, most trials of MAO-B inhibitors demonstrate benefit, including DATATOP, TEMPO, and ADAGIO in early PD, as well as PRESTO and LARGO in advanced PD. ${ }^{13,18,20,27,28}$ Another measure of disability, the Columbia University Disability Scale, showed benefit in a small, 12-week crossover study of subjects receiving selegiline for advanced PD. ${ }^{31}$ Although shorter trials of MAO-B inhibitors indicate an improvement in disability as measured by the UPDRS Part II ADL 
subscale, two longer treatment trials of selegiline either showed only trends toward improvement on the UPDRS Part II ADL subscale s2 $^{32}$ or no difference in disability on two separate disability scales (Webster Disability Scale ${ }^{33}$ and Northwestern University Disability Scale) ${ }^{34}$ in patients treated with selegiline plus carbidopa/levodopa versus carbidopa/levodopa alone. ${ }^{35}$

\section{Disease modification}

Both selegiline and rasagiline have preclinical neuroprotective effects. They prevent apoptosis through upregulation of Bcl-2 and Bcl-XL (antiapoptotic proteins), nerve growth factor, brain-derived neurotrophic factor, ciliary neurotrophic factor, glial-derived neurotrophic factor, glutathione, and other antioxidants and trophic factors. ${ }^{36-41}$ Selegiline and rasagiline both specifically protect dopaminergic neurons in culture from salsolinol, a neurotoxin. ${ }^{42-45}$ Additionally, rasagiline is neuroprotective in primate 1-methyl-4-phenyl1,2,3,6-tetrahydropyridine and rodent 6-hydroxydopamine models of parkinsonism. ${ }^{46,47}$ Selegiline and rasagiline are both protective in rodent brain ischemia models. ${ }^{48,49}$ The putative neuroprotective benefits of both agents are separate from the MAO-B inhibition. Due to the abundance of preclinical work, there has been considerable interest in these agents' potential as neuroprotective therapies for PD. When interpreting results from these trials, it is worthwhile to note that the clinical effects seen are best referred to as disease modification rather than neuroprotection, as neuroprotection implies direct knowledge of the effect at a cellular level. "Disease modification" is a more accurate term for clinical changes observed in a trial setting beyond that which can be explained by the direct symptomatic benefit.

The earliest large trial of selegiline, DATATOP, was undertaken with the objective of finding a disease-modifying therapy for PD, on the assumption that selegiline itself did not have symptomatic benefit in PD. ${ }^{13}$ Because the investigators did not realize that selegiline would have a definite symptomatic benefit, the study design was not adequate to determine whether there was a disease-modifying effect. This unexpected confounder "hampers a clear-cut detection of potentially protective actions of this monoamine oxidase inhibitor". ${ }^{13}$ A retrospective, pharmacological model-based analysis of the DATATOP study suggested a "functional protective effect of deprenyl". ${ }^{50}$ However, without a new, large study with a different study design, the question of whether the preclinical neuroprotective effects of selegiline are translatable to the bedside will remain controversial. ${ }^{14}$
With the confounder of symptomatic therapy in mind, a new study design was proposed to evaluate rasagiline's possible disease-modifying benefits. The study design is referred to as a delayed-start trial design. ${ }^{51}$ The essence of the delayed-start design is that of a two-arm, placebocontrolled, double-blinded, randomized trial that has two phases. In phase 1, the two groups are randomized to active compound or placebo. In phase 2 , subjects and investigators remain blinded to the original allocation, but all subjects begin active treatment. The endpoints for the trial design are complex, requiring that the groups are different at the end of phase 2, that the groups' outcomes were not converging during the second phase of the trial, and that the outcome data were diverging during phase 1. The study design has potential pitfalls, including, first and foremost, complexity, reliance on complete data from the first phase of the trial, and assumption that the disease progresses linearly. ${ }^{51}$ With these caveats in mind, the delayed-start design was used in the ADAGIO study in an attempt to show that rasagiline's preclinical neuroprotective effects occur in vivo.

The results of the ADAGIO study were, unfortunately, controversial. ${ }^{52-55}$ The study employed the delayed-start trial design with two different doses of rasagiline: $1 \mathrm{mg}$ and $2 \mathrm{mg}$. ${ }^{20}$ The $1 \mathrm{mg}$ dose is most commonly used in clinical practice, whereas the $2 \mathrm{mg}$ dose showed possible disease-modifying effects in a previous trial, TEMPO ${ }^{18}$ The results of the ADAGIO study were mixed, with the $1 \mathrm{mg}$ dose meeting all of the primary endpoints and the $2 \mathrm{mg}$ dose failing to do so, presumably due to "greater symptomatic benefit". ${ }^{52}$ However, the relevance of the $1 \mathrm{mg}$ dose's effect is not clear. Although the results for the $1 \mathrm{mg}$ dose reached statistical significance, there is a strong argument against the clinical significance of the result. The difference on the T-UPDRS attributable to the possible disease-modifying effect of rasagiline was only 1.7 points, which is substantially less than the 4.3 needed for a patient to notice a minimal CID. ${ }^{11}$ The ADAGIO study authors' final conclusion was: "We cannot definitively conclude that rasagiline at a dose of $1 \mathrm{mg}$ per day has diseasemodifying effects. It will be important to determine whether these results can be confirmed and whether benefits seen at 18 months will endure and translate into reduced cumulative disability". ${ }^{20}$

There is a possibility that the benefits of early treatment with rasagiline will accumulate and provide a more meaningful difference over years of treatment, but based on current evidence, rasagiline cannot be said to definitively have a disease-modifying effect. ${ }^{53,56}$ 


\section{Safety of MAO-B inhibitors Adverse effects}

The safety profile of the MAO-B inhibitors, in general, is favorable. They are generally well tolerated with few serious side effects, but there are a number of theoretical adverse reactions and interactions. ${ }^{57}$ Typical side effects of treatment with selegiline include dry mouth, anxiety, sleep disturbances, confusion, nausea, dizziness, orthostatic hypotension, and hallucinations. ${ }^{58-61}$ When used in combination with levodopa in advanced PD, selegiline may cause dyskinesia and is more likely to cause orthostatic hypotension. Elevated liver function tests have been reported but are rare enough that regular monitoring of liver function is not performed in clinical practice. ${ }^{61}$ Selegiline is metabolized to amphetamines, which may be cardiotoxic. ${ }^{62}$ Zydis selegiline, an orally dissolving tablet, does not produce the same level of amphetamine metabolites as conventional selegiline, but the clinical significance of this is unknown. ${ }^{17}$

Rasagiline, like selegiline, is well tolerated. In fact, in the TEMPO study, which enrolled patients with early PD, side effects occurred at the same rate in the active treatment and placebo arms. The most common side effects were headache, infection, dizziness, nausea, and pain. ${ }^{18}$ Rasagiline appears to be quite safe for elderly patients (aged $>70$ years) as well, which is an important consideration given that the incidence of PD increases with age. ${ }^{63}$ In patients with advanced PD, side effects may be more common. In the PRESTO study, rasagiline was more likely than placebo to cause vomiting, weight loss, anorexia, and balance difficulties. ${ }^{27}$ Treatment discontinuation due to adverse events has been low in all of the large, randomized trials of rasagiline. ${ }^{64}$

\section{Hypertensive crisis}

A theoretical risk of treatment with MAO inhibitors is the so-called "cheese effect" or tyramine effect, which can lead to hypertensive crisis. Hypertensive crisis may be seen when patients treated with nonselective MAO inhibitors eat foods rich in tyramine, such as aged cheese and red wine. ${ }^{65}$ MAO-A usually metabolizes tyramine, a norepinephrine precursor, in the intestine. However, if MAO-A is inhibited in sufficient amounts, then tyramine can be absorbed, leading to elevated levels of norepinephrine and hypertensive crisis. At the $10 \mathrm{mg}$ dose commonly used to treat PD, selegiline is quite selective for MAO-B and does not lead to the "cheese effect", even when directly challenged with tyramine. ${ }^{66,67}$ Selegiline does, however, still carry a warning on its label regarding the "cheese effect", because, if used at higher doses, it loses its selectivity and may precipitate hypertensive crisis. ${ }^{68}$ Rasagiline is more selective for MAO-B than is selegiline, and may have a greater margin of safety if used above recommended dosages. ${ }^{69}$ There have been a number of studies examining the effects of tyramine administered with rasagiline, and the safety data from these trials have led to the removal of the "cheese effect" warning from the rasagiline label. ${ }^{69,70}$

\section{Serotonin syndrome}

The serotonin syndrome consists of core clinical features of fever, myoclonus, and altered mental status. ${ }^{71}$ Additional features may include hyperreflexia, diarrhea, ataxia, tremor, mood alteration, and shivering. ${ }^{72}$ Originally described in patients taking nonselective MAO inhibitors, ${ }^{73}$ it is now most commonly seen in patients taking more than one drug with serotonergic activity (often selective serotonin reuptake inhibitors [SSRIs] or tricyclic antidepressants in combination with MAO inhibitors). ${ }^{74}$ Treatment generally consists of supportive care and discontinuing the offending agent. ${ }^{75}$ Though serotonin syndrome is potentially quite dangerous, there does not appear to be a serious risk of developing it while taking selective MAO-B at PD doses, even when taking an SSRI as well. Two retrospective studies have failed to show evidence of serotonin syndrome in patients taking selegiline and an SSRI. ${ }^{75,76} \mathrm{~A}$ survey of members of the Parkinson Study Group found 4568 PD patients treated with a combination of selegiline and an SSRI. Of those, $11(0.24 \%)$ were found to have symptoms consistent with serotonin syndrome; two $(0.04 \%)$ had symptoms deemed to be serious. ${ }^{77}$ So the risk of serotonin syndrome with selegiline appears minimal. Data on the use of rasagiline and SSRI in patients with PD are lacking; however, given the higher specificity of rasagiline for MAO-B than selegiline, it is unlikely that rasagiline has a high likelihood of causing serotonin syndrome. In at least one small study of healthy volunteers given escitalopram and rasagiline, there were no symptoms consistent with serotonin syndrome. ${ }^{78}$

\section{Patient preference Adherence}

Adherence to a prescribed medical regimen is crucial to successful treatment. Both underuse and overuse of medication are problematic in PD. Overuse of medications is predominantly seen in patients taking dopamine agonists or levodopa, not MAO-B inhibitors. ${ }^{79-83}$ Underuse of PD medications is more common than overuse ${ }^{84}$ and may be seen with any class of antiparkinsonian therapy, leading to worsening bradykinesia and rigidity ${ }^{85}$ Another theoretical 
concern regarding irregular adherence is that pulsatile dopaminergic stimulation may increase the risk of motor fluctuations. ${ }^{86,87}$ In the largest study to date on adherence to antiparkinsonian medication, there were a number of factors associated with adherence. ${ }^{85}$ Patients with motor fluctuations, more severe disease, and worse mobility had poorer adherence to prescribed regimens. ${ }^{88}$ Medications that could be taken once daily had significantly higher total therapy adherence, higher number of days of adherence, and higher adherence to dose timing than medications prescribed three times per day. ${ }^{88}$ Twice-daily dosing also held advantages in total adherence and number of days of adherence when compared with more complex regimens. ${ }^{88}$ Based on the available data, MAO-B inhibitors with once-daily and twice-daily dosing likely have better patient adherence in clinical practice than medications that require more frequent dosing.

\section{Quality of life}

Another factor that may influence patient preference of a treatment regimen is QOL. Indirect data would suggest that MAO-B inhibitors improve QOL, as more complex drug regimens are associated with lower QOL. ${ }^{84} \mathrm{QOL}$ assessments have only recently become standard additions to clinical trials in $\mathrm{PD}$, in part due to the increasing focus on nonmotor symptoms and other contributors to QOL in PD. ${ }^{29,89,90}$ Available trial data examining QOL in patients taking MAO-B inhibitors are mixed. Older trials of selegiline sometimes presumed that QOL improved based on a reduction in disease severity or motor fluctuations, ${ }^{91}$ but more recent trials have confirmed that selegiline improves QOL in patients with motor fluctuations. ${ }^{92}$ A predetermined subset of subjects enrolled in the TEMPO study (early PD) of rasagiline found that rasagiline improved QOL in PD. The analysis concluded that the effects of rasagiline are not fully explained by observed improvement in UPDRS and may represent antidepressant or other effects. ${ }^{93}$ However, the PRESTO study (advanced PD) on rasagiline failed to show any benefit in regard to QOL. ${ }^{27}$ Unlike the findings from PRESTO, postmarketing observational studies of rasagiline in advanced $\mathrm{PD}$ with motor fluctuations have suggested that rasagiline improves QOL. ${ }^{94}$ Given the nature of postmarketing, open-label studies, these findings should be interpreted with caution.

\section{Conclusion}

The use of MAO-B inhibitors for the symptomatic treatment of PD is widespread. In early PD, these medications are safe and very well tolerated, though their efficacy is only modest.
Although theoretical concerns exist regarding serious adverse events such as serotonin syndrome and hypertensive crisis, these problems are very unlikely to occur if the MAO-B inhibitors are used as recommended. Beyond their symptomatic benefits for PD, there is a possibility that MAO-B inhibitors have a disease-modifying effect. This remains a controversial topic, and it is left up to the individual clinician to decide whether or not to prescribe the drug with disease modification as the goal. Patient adherence is another important factor that impacts outcomes in PD treatment. Because of their simple dosing schedules, MAO-B inhibitors are more likely to be accepted by patients and taken as prescribed than other dopaminergic agents with more complex dosing schedules. At least partly through their symptomatic amelioration of PD symptoms, MAO-B inhibitors are also likely to improve QOL in PD.

\section{Disclosure}

The author reports no conflicts of interest in this work.

\section{References}

1. Tanner CM, Aston DA. Epidemiology of Parkinson's disease and akinetic syndromes. Curr Opin Neurol. 2000;13:427.

2. Miyasaki JM, Martin W, Suchowersky O, et al. Practice parameter: initiation of treatment for parkinson's disease: an evidence-based review. Report of the Quality Standards Subcommittee of the American Academy of Neurology. Neurology. 2002;58(1):11-17.

3. Pahwa R, Factor SA, Lyons KE, et al. Practice parameter: treatment of Parkinson disease with motor fluctuations and dyskinesia (an evidencebased review). Report of the Quality Standards Subcommittee of the American Academy of Neurology. Neurology. 2006;66(7):983-995.

4. Hoffman BB, Lefkowitz RJ. Catecholamines, sympoathomimetic drugs, and adrenergic receptor antagonists. In: Hardman JG, Limbird LE, Goodman Gilman A, et al, editors. Goodman and Gilman's The Pharmacological Basis of Therapeutics. New York: McGraw-Hill; 1996:199-248.

5. Rajput A, Zesiewicz TA, Hauser RA. Monoamine oxidase inhibitors. In: Factor SA, Weiner WJ, editors. Parkinson's Disease: Diagnosis and Clinical Management. New York: Demos Medical Publishing; 2008:499-513.

6. Fowler CJ, Tipton KF. On the substrate specificities of the two forms of monoamine oxidase. J Pharm Pharmacol. 1984;36(2):111-115.

7. Rohatagi S, Barrett JS, deWitt KE, Morales RJ. Integrated pharmacokinetic and metabolic modeling of selegiline and metabolites after transdermal administration. Biopharm Drug Dispos. 1997;18(7): $567-584$.

8. Doller HJ, Connor JD. Changes in neostriatal dopamine concentrations in response to levodopa infusions. J Neurochem. 1980; 34(5):1264-1269.

9. Lewitt PA. MAO-B inhibitor know-how: back to the pharm. Neurology. 2009;72(15):1352-1357.

10. Goetz CG, Stebbins GT, Chmura TA, et al. Teaching tape for the motor section of the unified Parkinson's Disease Rating Scale. Mov Disord. 1995;10(3):263-266.

11. Shulman LM, Gruber-Baldini AL, Anderson KE, et al. The clinically important difference on the unified Parkinson's Disease Rating Scale. Arch Neurol. 2010;67(1):64-70.

12. Hauser RA, Friedlander J, Zesiewicz TA, et al. A home diary to assess functional status in patients with Parkinson's disease with motor fluctuations and dyskinesia. Clin Neuropharmacol. 2000;23(2):75-81. 
13. Effects of tocopherol and deprenyl on the progression of disability in early Parkinson's disease. The Parkinson Study Group. N Engl J Med. 1993;328(3):176-183.

14. Palhagen S, Heinonen EH, Hagglund J, et al. Selegiline delays the onset of disability in de novo parkinsonian patients. Swedish Parkinson Study Group. Neurology. 1998;51(2):520-525

15. Tetrud JW, Langston JW. The effect of deprenyl (selegiline) on the natural history of Parkinson's disease. Science. 1989;245(4917):519-522.

16. Myllyla VV, Sotaniemi KA, Vuorinen JA, Heinonen EH. Selegiline in de novo parkinsonian patients: The Finnish Study. Mov Disord. 1993; 8 Suppl 1:S41-S44.

17. Clarke A. A new low-dose formulation of selegiline: clinical efficacy, patient preference and selectivity for MAO-B inhibition. J Neural Transm. 2003;110(11):1257.

18. Parkinson Study Group. A controlled trial of rasagiline in early Parkinson disease: the TEMPO study. Arch Neurol. 2002;59(12):1937-1943.

19. Olanow CW, Rascol O, Hauser R, et al. A double-blind, delayed-start trial of rasagiline in Parkinson's disease. N Engl J Med. 2009; 361(13):1268-1278.

20. Olanow CW, Rascol O, Hauser R, et al. A double-blind, delayed-start trial of rasagiline in Parkinson's disease. $N$ Engl J Med. 2009; 361(13):1268-1278.

21. Heinonen EH, Rinne UK. Selegiline in the treatment of Parkinson's disease. Acta Neurol Scand Suppl. 1989;126:103-111.

22. Lees AJ. Current controversies in the use of selegiline hydrochloride J Neural Transm Suppl. 1987;25:157-162.

23. Golbe LI, Lieberman AN, Muenter MD, et al. Deprenyl in the treatment of symptom fluctuations in advanced Parkinson's disease. Clin Neuropharmacol. 1988;11(1):45-55.

24. Waters CH, Sethi KD, Hauser RA, et al. Zydis Selegiline Study Group Zydis selegiline reduces off time in Parkinson's disease patients with motor fluctuations: a 3-month, randomized, placebo-controlled study. Mov Disord. 2004;19(4):426-432.

25. Shoulson I, Oakes D, Fahn S, et al. Impact of sustained deprenyl (selegiline) in levodopa-treated Parkinson's disease: a randomized placebo-controlled extension of the Deprenyl and Tocopherol Antioxidative Therapy of Parkinsonism Trial. Ann Neurol. 2002;51(5): 604-612.

26. Lieberman AN, Gopinathan G, Neophytides A, Foo SH. Deprenyl versus placebo in Parkinson disease: a double-blind study. NY State J Med. 1987;87(12):646-649.

27. Parkinson Study Group. A randomized placebo-controlled trial of rasagiline in levodopa-treated patients with Parkinson disease and motor fluctuations: the PRESTO study. Arch Neurol. 2005;62(2): 241-248.

28. Rascol O, Brooks DJ, Melamed E, et al. Rasagiline as an adjunct to levodopa in patients with Parkinson's disease and motor fluctuations (LARGO, Lasting Effect in Adjunct Therapy with Rasagiline Given Once Daily Study): a randomised, double-blind, parallel-group trial Lancet. 2005;365(9463):947-954.

29. Shulman LM, Gruber-Baldini AL, Anderson KE, et al. The evolution of disability in Parkinson disease. Mov Disord. 2008;23(6):790-796.

30. Schawab RS, England AC Jr. Parkinson's disease: rehabilitation aspects. Rehabil Lit. 1961;22:326-236.

31. Heinonen EH, Rinne UK, Tuominen J. Selegiline in the treatment of daily fluctuations in disability of parkinsonian patients with long-term levodopa treatment. Acta Neurol Scand Suppl. 1989;126: 113-118.

32. Larsen JP, Boas J. The effects of early selegiline therapy on long-term levodopa treatment and parkinsonian disability: An interim analysis of a Norwegian-Danish 5-year study. Norwegian-Danish Study Group. Mov Disord. 1997;12(2):175-182.

33. Webster DD. Critical analysis of the disability in Parkinson's disease. Mod Treat. 1968;5(2):257-282.

34. Canter C, de la Torre R, Mier M. A method of evaluating disabilities in patients with Parkinson's disease. J Nerv Ment Dis. 1961; 133:143-147.
35. Lees AJ. Comparison of therapeutic effects and mortality data of levodopa and levodopa combined with selegiline in patients with early, mild Parkinson's disease. Parkinson's Disease Research Group of the United Kingdom. BMJ. 1995;311(7020):1602-1607.

36. Kluck RM, Bossy-Wetzel E, Green DR, Newmeyer DD. The release of cytochrome $\mathrm{C}$ from mitochondria: a primary site for bcl-2 regulation of apoptosis. Science. 1997;275(5303):1132-1136.

37. Shahani N, Gourie-Devi M, Nalini A, et al. (-)-Deprenyl alleviates the degenerative changes induced in the neonatal rat spinal cord by CSF from amyotrophic lateral sclerosis patients. Amyotroph Lateral Scler Other Motor Neuron Disord. 2004;5(3):172-179.

38. Carrillo MC, Minami C, Kitani K, et al. Enhancing effect of rasagiline on superoxide dismutase and catalase activities in the dopaminergic system in the rat. Life Sci. 2000;67(5):577-585.

39. Maruyama W, Yamamoto T, Kitani K, et al. Mechanism underlying anti-apoptotic activity of a (-)deprenyl-related propargylamine, rasagiline. Mech Ageing Dev. 2000;116(2-3):181-191.

40. Takahata K, Shimazu S, Katsuki H, et al. Effects of selegiline on antioxidant systems in the nigrostriatum in rat. J Neural Transm. 2006; 113(2):151-158

41. Finberg JP, Takeshima T, Johnston JM, Commissiong JW. Increased survival of dopaminergic neurons by rasagiline, a monoamine oxidase B inhibitor. Neuroreport. 1998;9(4):703-707.

42. Maruyama W, Akao Y, Carrillo MC, et al. Neuroprotection by propargylamines in Parkinson's disease: suppression of apoptosis and induction of prosurvival genes. Neurotoxicol Teratol. 2002; 24(5):675-682.

43. Sharma SK, Carlson EC, Ebadi M. Neuroprotective actions of selegiline in inhibiting 1-methyl, 4-phenyl, pyridinium ion (MPP+)-induced apoptosis in SK-N-SH neurons. J Neurocytol. 2003;32(4):329-343.

44. Ebadi M, Sharma S, Shavali S, et al. The multiple actions of selegiline. Proc West Pharmacol Soc. 2002;45:39-41.

45. Blandini F. Neuroprotection by rasagiline: a new therapeutic approach to Parkinson's disease? CNS Drug Rev. 2005;11(2):183-194.

46. Kupsch A, Sautter J, Gotz ME, et al. Monoamine oxidase-inhibition and MPTP-induced neurotoxicity in the non-human primate: comparison of rasagiline (TVP 1012) with selegiline. J Neural Transm. 2001; 108(8-9):985-1009.

47. Blandini F, Armentero MT, Fancellu R, et al. Neuroprotective effect of rasagiline in a rodent model of Parkinson's disease. Exp Neurol. 2004; 187(2):455-459.

48. Simon L, Szilagyi G, Bori Z, et al. (-)-D-deprenyl attenuates apoptosis in experimental brain ischaemia. Eur J Pharmacol. 2001; 430(2-3):235-241.

49. Speiser Z, Mayk A, Eliash S, Cohen S. Studies with rasagiline, a MAO-B inhibitor, in experimental focal ischemia in the rat. J Neural Transm. 1999;106(7-8):593-606.

50. Holford NH, Chan PL, Nutt JG, et al. Parkinson Study Group. Disease progression and pharmacodynamics in Parkinson disease: evidence for functional protection with levodopa and other treatments. J Pharmacokinet Pharmacodyn. 2006;33(3):281-311.

51. D'Agostino RB. The delayed-start study design. $N$ Engl J Med. 2009;361(13):1304-1306.

52. Olanow CW, Rascol O. The delayed-start study in Parkinson disease: can’t satisfy everyone. Neurology. 2010;74(14):1149-1150.

53. Ahlskog JE, Uitti RJ. Rasagiline, Parkinson neuroprotection, and delayed-start trials: still no satisfaction? Neurology. 2010;74(14): 1143-1148.

54. Ahlskog JE, Uitti RJ. Reply to Drs. Olanow and Rascol. Neurology. 2010;74(14):1151

55. Sampaio C, Ferreira JJ. Parkinson disease: ADAGIO trial hints that rasagiline slows disease progression. Nat Rev Neurol. 2010;6(3): 126-128.

56. Mehta SH, Morgan JC, Sethi KD. Does rasagiline have a disease-modifying effect on Parkinson's disease? Curr Neurol Neurosci Rep. 2010;10(6):413-416.

57. Heinonen EH. Safety of selegiline (deprenyl) in the treatment of Parkinsons disease. Drug Safety. 1998;19(1):11. 
58. Myllyla VV, Sotaniemi K, Maki-Ikola O, et al. Role of selegiline in combination therapy of Parkinson's disease. Neurology. 1996 Dec; 47(6 Suppl 3):S200-S209.

59. Elizan TS, Moros DA, Yahr MD. Early combination of selegiline and low-dose levodopa as initial symptomatic therapy in Parkinson's disease: experience in 26 patients receiving combined therapy for 26 months. Arch Neurol. 1991;48(1):31-34.

60. Golbe LI. Long-term efficacy and safety of deprenyl (selegiline) in advanced Parkinson's disease. Neurology. 1989;39(8):1109-1111.

61. Waters CH. Side effects of selegiline (eldepryl). J Geriatr Psychiatry Neurol. 1992;5(1):31-34.

62. Churchyard A, Mathias CJ, Boonkongchuen P, Lees AJ. Autonomic effects of selegiline: possible cardiovascular toxicity in Parkinson's disease. J Neurol Neurosurg Psychiatry. 1997;63(2):228-234.

63. Goetz CG, Schwid SR, Eberly SW, et al; Parkinson Study Group TEMPO and PRESTO Investigators. Safety of rasagiline in elderly patients with Parkinson disease. Neurology. 2006;66(9):1427-1429.

64. Leegwater-Kim J, Bortan E. The role of rasagiline in the treatment of Parkinson's disease. Clin Interv Aging. 2010;5:149-156.

65. Marley E, Blackwell B. Interactions of monoamine oxidase inhibitors, amines, and foodstuffs. Adv Pharmacol Chemother. 1970;8:185-349.

66. Elsworth JD, Glover V, Reynolds GP, et al. Deprenyl administration in man: a selective monoamine oxidase B inhibitor without the 'cheese effect'. Psychopharmacology (Berl). 1978;57(1):33-38.

67. Schulz R. Tyramine kinetics and pressor sensitivity during monoamine oxidase inhibition by selegiline. Clin Pharmacol Ther. 1989; 46(5):528.

68. Heinonen EH, Lammintausta R. A review of the pharmacology of selegiline. Acta Neurol Scand Suppl. 1991;136:44-59.

69. Goren T. Clinical pharmacology tyramine challenge study to determine the selectivity of the monoamine oxidase type B (MAO-B) inhibitor rasagiline. J Clin Pharmacol. 2010;50(12):1420-1428.

70. deMarcaida JA. Effects of tyramine administration in Parkinson's disease patients treated with selective MAO-B inhibitor rasagiline. Mov Disord. 2006;21(10):1716.

71. Sternbach H. The serotonin syndrome. Am J Psychiatry. 1991;148(6): 705-713.

72. Radomski JW, Dursun SM, Reveley MA, Kutcher SP. An exploratory approach to the serotonin syndrome: an update of clinical phenomenology and revised diagnostic criteria. Med Hypotheses. 2000; 55(3): $218-224$.

73. Oates JA, Sjoerdsma A. Neurologic effects of tryptophan in patients receiving a monoamine oxidase inhibitor. Neurology. 1960; 10:1076-1078.

74. Mason PJ, Morris VA, Balcezak TJ. Serotonin syndrome. presentation of 2 cases and review of the literature. Medicine (Baltimore). 2000; 79(4):201-209.

75. Waters $\mathrm{CH}$. Fluoxetine and selegiline: lack of significant interaction. Can J Neurol Sci. 1994;21(3):259-261.

76. Feighner JP, Boyer WF, Tyler DL, Neborsky RJ. Adverse consequences of fluoxetine-MAOI combination therapy. J Clin Psychiatry. 1990; 51(6):222-225.

77. Richard IH, Kurlan R, Tanner C, et al. Serotonin syndrome and the combined use of deprenyl and an antidepressant in Parkinson's disease. Parkinson Study Group. Neurology. 1997;48(4):1070-1077.
78. Hilli J, Korhonen T, Laine K. Lack of clinically significant interactions between concomitantly administered rasagiline and escitalopram. Prog Neuropsychopharmacol Biol Psychiatry. 2009;33(8):1526-1532.

79. Evans AH, Katzenschlager R, Paviour D, et al. Punding in Parkinson's disease: its relation to the dopamine dysregulation syndrome. Mov Disord. 2004;19(4):397-405.

80. Evans AH, Lawrence AD, Cresswell SA, et al. Compulsive use of dopaminergic drug therapy in Parkinson's disease: reward and anti-reward. Mov Disord. 2010;25(7):867-876.

81. Evans AH, Lawrence AD, Potts J, et al. Factors influencing susceptibility to compulsive dopaminergic drug use in Parkinson disease. Neurology. 2005;65(10):1570-1574.

82. Giovannoni G, O'Sullivan JD, Turner K, et al. Hedonistic homeostatic dysregulation in patients with Parkinson's disease on dopamine replacement therapies. J Neurol Neurosurg Psychiatry. 2000;68(4):423-428.

83. Lawrence AD, Evans AH, Lees AJ. Compulsive use of dopamine replacement therapy in Parkinson's disease: reward systems gone awry? Lancet Neurol. 2003;2(10):595-604.

84. Grosset D, European PD Therapy Compliance Study Group. Therapy adherence issues in Parkinson's disease. J Neurol Sci. 2010; 289(1-2):115-118.

85. Grosset D, Antonini A, Canesi M, et al. Adherence to antiparkinson medication in a multicenter european study. Mov Disord. 2009; 24(6):826-832.

86. Olanow CW, Obeso JA, Stocchi F. Drug insight: continuous dopaminergic stimulation in the treatment of Parkinson's disease. Nat Clin Pract Neurol. 2006;2(7):382-392.

87. Stocchi F, Vacca L, Ruggieri S, Olanow CW. Intermittent vs continuous levodopa administration in patients with advanced Parkinson disease: a clinical and pharmacokinetic study. Arch Neurol. 2005; 62(6):905-910.

88. Grosset D, Antonini A, Canesi M, et al. Adherence to antiparkinson medication in a multicenter European study. Mov Disord. 2009; 24(6):826-832.

89. Zesiewicz TA, Sullivan KL, Arnulf I, et al. Practice parameter: treatment of nonmotor symptoms of Parkinson disease. Report of the Quality Standards Subcommittee of the American Academy of Neurology. Neurology. 2010;74(11):924-931.

90. Gruber-Baldini AL, Ye J, Anderson KE, Shulman LM. Effects of optimism/pessimism and locus of control on disability and quality of life in Parkinson's disease. Parkinsonism Relat Disord. 2009; 15(9):665-669.

91. Bryson HM, Milne RJ, Chrisp P. Selegiline: an appraisal of the basis of its pharmacoeconomic and quality-of-life benefits in Parkinson's disease. Pharmacoeconomics. 1992;2(2):118-136.

92. Lyons KE, Friedman JH, Hermanowicz N, et al. Orally disintegrating selegiline in Parkinson patients with dopamine agonist-related adverse effects. Clin Neuropharmacol. 2010;33(1):5-10.

93. Biglan KM, Schwid S, Eberly S, et al. Rasagiline improves quality of life in patients with early Parkinson's disease. Mov Disord. 2006; 21(5):616-623.

94. Jost WH, Klasser M, Reichmann H. Rasagiline in daily clinical use: results of a treatment study of Parkinson patients with a combination treatment. Fortschr Neurol Psychiatr. 2008;76(10):594-599.
Patient Preference and Adherence

\section{Publish your work in this journal}

Patient Preference and Adherence is an international, peer-reviewed, open access journal focusing on the growing importance of patient preference and adherence throughout the therapeutic continuum. Patient satisfaction, acceptability, quality of life, compliance, persistence and their role in developing new therapeutic modalities and compounds to

\section{Dovepress}

optimize clinical outcomes for existing disease states are major areas of interest. This journal has been accepted for indexing on PubMed Central. The manuscript management system is completely online and includes a very quick and fair peer-review system. Visit http://www.dovepress.com/ testimonials.php to read real quotes from published authors. 